\title{
STUDENT-ATHLETE MIGRATION: A SYSTEMATIC LITERATURE REVIEW
}

review paper

( ) University School of Physical Education in Wroclaw

DOI: https://doi.org/10.5114/hm.2021.99988

\author{
FEDERICO PALUMBO ${ }^{1}$, ANDREA FUSCO ${ }^{2}$, CRISTINA CORTIS $^{2}$, LAURA CAPRANICA ${ }^{1}$ \\ ${ }^{1}$ Department of Movement, Human and Health Sciences, University of Rome "Foro Italico", Rome, Italy \\ ${ }^{2}$ Department of Human Sciences, Society and Health, University of Cassino and Lazio Meridionale, Cassino, Italy
}

\begin{abstract}
Purpose. The continuous migration of student-athletes to pursue their educational and sport careers (i.e., dual career) urges the scientific community to investigate this phenomenon. To provide a systematic literature review on migrating studentathletes, this review framed the research questions, identified relevant scientific contributions, assessed the quality of the studies, summarized evidence, and interpreted the findings.

Methods. A systematic review conducted in accordance with preferred reporting items for systematic reviews and metaanalyses guidelines returned 1208 records from 2007 to 2019. After screening for the set criteria, only 12 papers met the final inclusion criteria.

Results. Few eligible papers highlight limited interest in dual career athletic migration. Furthermore, a lack of a dual career friendly environment supporting the combination of educational (university or high school) and high-level sports opportunities in the native country emerged as the main reason for student-athletes migration. In fact, American colleges, offering optimal opportunities to accomplish education and sport, turned out to be the most represented migration sites, which also satisfy the student-athletes' desire to attain high-quality education, their willingness to live in another country and to practise sports at high levels.
\end{abstract}

Conclusions. In the context of the pervasive globalization of sport and education, to contribute to the development of the European dual career sports culture, further research is needed to empirically examine the migration phenomenon of European student-athletes in Member States.

Key words: dual career, education, sport, incoming country, push-pull factors, outgoing country

\section{Introduction}

A long process is needed to become an elite athlete, starting at young ages and spanning till adulthood, and undergoing increasing volume, frequency, and intensity of training to progress in sports competitions from local to national and international levels. Therefore, to pursue excellence in sports performance, high-level athletes highly commit to training and competition, including the extra time required to transfer from and to the training and competition venues [1]. During their developmental years, athletes face several career transitions at the athletic, psychological, psychosocial, academic/vocational, and financial levels occurring at different time, interacting with each other in various modalities, and having different impacts on the athletes depending on their athletic levels (e.g., sub-elite and elite) and the sports discipline [2, 3]. In particular, youth talented athletes often struggle in combining successfully their sports and academic careers (e.g., dual career), which could enable their holistic development $[4,5]$ and enhance their transition from sport to the labour market at the end of their competitive years $[6,7]$.

The European Commission [6] and the European Parliament [8-10] highly recognize the elite athletes as they represent the Member States and have strategic roles in promoting the social and economic growth of sports culture [11-13]. Considering that athletes face numerous challenges in managing their dual careers,

Correspondence address: Cristina Cortis, Via S. Angelo - Località Folcara, 03043 Cassino (FR), Italy, e-mail: c.cortis@unicas.it

Received: June 5, 2020

Accepted for publication: August 27, 2020

Citation: Palumbo F, Fusco A, Cortis C, Capranica L. Student-athlete migration: a systematic literature review. Hum Mov. 2021;22(1):80-91; doi: https://doi.org/10.5114/hm.2021.99988. 
the European Commission published the European Union (EU) guidelines on dual careers of athletes [14] with the aim of encouraging Member States to establish an effective cooperation between sports bodies and educational institutions or business-oriented companies to meet the demands of elite student/worker-athlete. In light of the relevant differences in dual career policies [15], services [16], and recognitions [17] among Member States, unequal treatment of European athletes might occur due to country-specific and culturalorganizational regulations in the field of sport and education. Furthermore, dual career could be even more problematic when athletes relocate (or migrate), in the context of the geographical direction and motivation to pursue their sports and/or academic career [18].

To provide European youth with the education, skills, and creativity needed in a knowledge society, the EuRopean community Action Scheme for the Mobility of University Students (ERASMUS) programme strongly supported mobility as the principal tool for building a European identity and citizenship through the area of education for the personal progression of European youth [19]. Since its establishment in 1987, improvements in the ERASMUS programme have concerned the credit assessment and credit recognition process, the preparations of students prior to their departure, and the academic, administrative, and financial support of students whilst abroad [20]. The globalization phenomenon, consolidating the world into a whole space, has been also beneficial for sport [21]. In fact, mobility strongly characterizes sport through extended networks developed to search for talented athletes on a global scale [22], and with both youth and top athletes increasingly considering migration as a relevant opportunity for athletic progression [23]. Thus, a growing number of athletes relocate within a country or migrate to another country, establishing connection networks [24] and/or enhancing their opportunity of sport labour migration [25, 26].
In a globalized world, international education exchanges are considered valuable opportunities to empower youth talented individuals by fostering cultural exchanges of ideas, best practices, challenges, opportunities, mutual understanding, and international goodwill. Since the seminal establishment of the Fulbright Scholar Program at the end of World War II [27], other open and merit-based programmes have been developed [28]. In Europe, the ERASMUS+ programme represents crucial opportunities for exchanges and contamination of the full diversity of Member States [29].

Specifically related to student-athletes in American colleges, 6 typologies of student-athlete migration have been identified [30]: (1) Mercenary, which refers to athletes motivated by the associated economic reward for their talent; (2) Settler, which refers to athletes who moved and remained in a host country for a prolonged period, also beyond the finish of their competitive careers; (3) Returnee, which refers to athletes who move back to their native country at the end of their studentathlete career; (4) Nomadic Cosmopolitan, which refers to athletes motivated by a desire to experience different countries and cultures; (5) Ambitionist, which refers to athletes having a strong desire to achieve a professional sports career by migrating in countries offering a better quality dual career environment; and (6) Exile, which refers to athletes voluntarily migrating for personal (liberty, domestic threats, personal life) or political reasons (Table 1). Although European student mobility [31] and athletic migration [18] are growing fields of research, there is a need to systematize the motivations and challenges encountered by migrating student-athletes in combining their athletic and academic paths.

In the last decades, the European Commission allocated a relevant budget to the ERASMUS+ programme in support of transnational collaborative partnerships related to strategic issues in sport, including dual career [32]. Recently, the collaborative efforts of 5 major Eu-

Table 1. Typology of migrant student-athlete [30]

\begin{tabular}{ll}
\hline Mercenary & Athletes motivated by the associated economic reward for their talent \\
\hline Settler & $\begin{array}{l}\text { Athletes who moved and remained in a host country for a prolonged period, also beyond } \\
\text { the finish of their competitive careers }\end{array}$ \\
\hline Returnee & Athletes who move back to their native country at the end of their student-athlete career \\
\hline Nomadic Cosmopolitan & Athletes motivated by a desire to experience different countries and cultures \\
\hline Ambitionist & $\begin{array}{l}\text { Athletes having a strong desire to achieve a professional sports career by migrating } \\
\text { in countries offering a better quality dual career environment }\end{array}$ \\
\hline Exile & $\begin{array}{l}\text { Athletes voluntarily migrating for personal (liberty, domestic threats, personal life) } \\
\text { or political reasons }\end{array}$ \\
\hline
\end{tabular}


F. Palumbo, A. Fusco, C. Cortis, L. Capranica, Student-athlete migration: a systematic literature review

ropean universities (e.g., the University of Salzburg, Austria; the University Sport Service of Hamburg, Germany; the Lapland University of Applied Sciences, Finland; the University of Cassino and Lazio Meridionale, Italy; and the University of Ljubljana, Slovenia) and the European dual career network (European Athlete as Student, Malta) specifically addressed the topic 'Athletic Migration: Dual Career and Qualification in Sports' (AMiD; 590400-EPP-1-2017-1-AT-SPO-SCP). In particular, $\mathrm{AMiD}$ aimed to promote and support good governance in sport and higher education of migrating student-athletes by building a network for exchange of best practices and developing their skills and competences, with special reference to the student-athletes' decision to leave the country (push factors), to look abroad and study in a specific country (pull factors), and to select a specific academic institution on the basis of the push/pull factors [18].

Therefore, within the AMiD project, the purpose of the present systematic analysis of the current scientific literature was to establish and critically appraise the existing relevant scientific contributions on the dual career of migrating student-athletes.

\section{Material and methods}

The present review on the dual career of migrating athletes encompassed 5 steps [33, 34]. In particular, step 1 consisted in framing the questions for the review; step 2 involved the identification of relevant works; step 3 implied the assessment of the quality of studies; step 4 incorporated the summary of the evidence; and step 5 concerned the interpretation of the findings. Two researchers belonging to the AMiD consortium were involved independently in all the exclusions or inclusions in the systematic review process (e.g., by the titles, the abstracts, and the full texts). Before the final inclusion or exclusion, a common decision was reached for each study. In the case of any doubt or uncertainty, a third expert was consulted. With the consideration of the first official appearance of the term 'dual career' [6], a chronological interval between 2007 and 2019 was set.

\section{Step 1: Framing the questions for the review}

This investigation was targeted to the dual career of athletes migrating for sports and/or academic reasons. In this study, athletic migration refers to an athlete's change of residence from one country to another country and not within one country. The a-priori-specified inclusion criteria to the main topic encompassed the following keywords: dual career OR student-athlet* AND international OR transnational OR relocation* AND migrant* OR migration* AND elite-athlet* OR globalization OR academic ${ }^{*}$. The asterisks ${ }^{*}$ ) were utilized to pull all derivations of the affiliated root word (i.e., athlet ${ }^{*}=$ athlete, athletes, etc.). To avoid any confounding outcome during the searching strategy, the authors agreed to consider the term 'migration' and 'relocation' as synonyms. However, scientific contributions focusing on student-athletes relocating within their home country were deemed not eligible for the present study.

\section{Step 2: Identification of relevant works}

A comprehensive identification of original manuscripts published in the English language was systematically performed in the Scopus, Institute for Scientific Information Web of Science (WoS), SPORTDiscus (EBSCOhost), and PsycArticles electronic databases. In particular, Scopus is the largest abstract and citation database of peer-reviewed literature in the fields of science, technology, medicine, social sciences, and arts and humanities; WoS is a subscription-based scientific citation indexing service giving access to multiple databases that reference cross-disciplinary research of scientific, technical, and social sciences literature; SPORTDiscus is a comprehensive database focused on sport, kinesiology, and allied science; PsycArticles is the full-text catalogue of American Psychological Association (APA) peer-reviewed journals covering psychology and allied fields. Eligibility was assessed by screening manuscripts firstly by titles, then by abstracts, and finally by full texts reading.

\section{Step 3: Assessment of the quality of studies}

For the assessment of the methodological quality of the selected papers, a 4-point Likert scale was applied to 9 appraisal questions: 'abstract and title,' 'introduction and aims,' 'method and data,' 'sampling,' 'data analysis,' 'ethics and bias,' 'results,' 'transferability or generalizability,' and 'implications and usefulness' [35], which were evaluated 'good' (4 points) when full and clear information was provided; 'fair' (3 points) when information was not complete or clear; 'poor' (2 points) when minimal or unclear information was present; or 'very poor' (1 point) when there was a lack of relevant information. Thus, total scores (ranging 9-36 points) were interpreted as high quality (30-36 points), medium quality (24-29 points), low quality (9-23 points) [36]. 


\section{Step 4: Summary of the evidence}

Each of the selected studies was assigned a bibliography code and data were extracted on a predefined form encompassing: author(s), publication year, original paper (yes/no), study purpose, study design (questionnaire, focus group, semi-structured interviews, interviews, case study, and a combination of these methods), sample size of migrant student-athletes, student-athletes not relocated, sex representation of migrant student-athletes, competition level, age, educational level, home country, country of migration, period of migration, main goal of migration (sports, academic, or both), main findings, other findings, limitations, future suggestions.

\section{Step 5: Interpretation of the findings}

To allow a synthesis of the relevant findings highlighted in the analysed manuscripts, a thematic analysis was deemed relevant for generating inferences, highlighting limitations, and suggesting future research.

\section{Ethical approval}

The conducted research is not related to either human or animal use.

\section{Results}

Figure 1 shows the PRISMA flow chart of the study selection process. From the initial set of 1208 identi- fied records, 474 duplicates were removed. After title and abstract reading, 575 and 130 records, respectively, were excluded because their content did not correspond with the goal of the present study. The subsequent full text reading of 29 papers excluded 7 additional items because they did not disclose clear and complete data, and 10 papers considering studentathletes relocating within the same country. Thus, a final list of 12 eligible papers was identified for data extraction.

After the publication of the White Paper on Sport [6], the interest toward the study of the dual career of migrating student-athletes started in 2010 and remained limited, and reached its peak ( $n=3$ studies) in 2011, with a lack of publications in the years of 2012, 2013, 2014, and 2017. The methodological approach to the problem included questionnaires [3741], semi-structured interviews [42-44], interviews $[18,30,45]$, and a combination of these methods (questionnaire and interview) [46]. In general, a wide sample size of migrating athletes was observed, with male athletes (75\%) outnumbering their female counterparts $(25 \%)$, and a lower number of participants included in the studies based on interviews ( $n$ range: 6-51) as compared with that of studies based on questionnaires ( $n$ range: 13-206).

One study did not specify the sport of the studentathletes [46], one article included only team sports athletes (basketball and soccer [41]), whereas the others encompassed several sports. Student-athletes

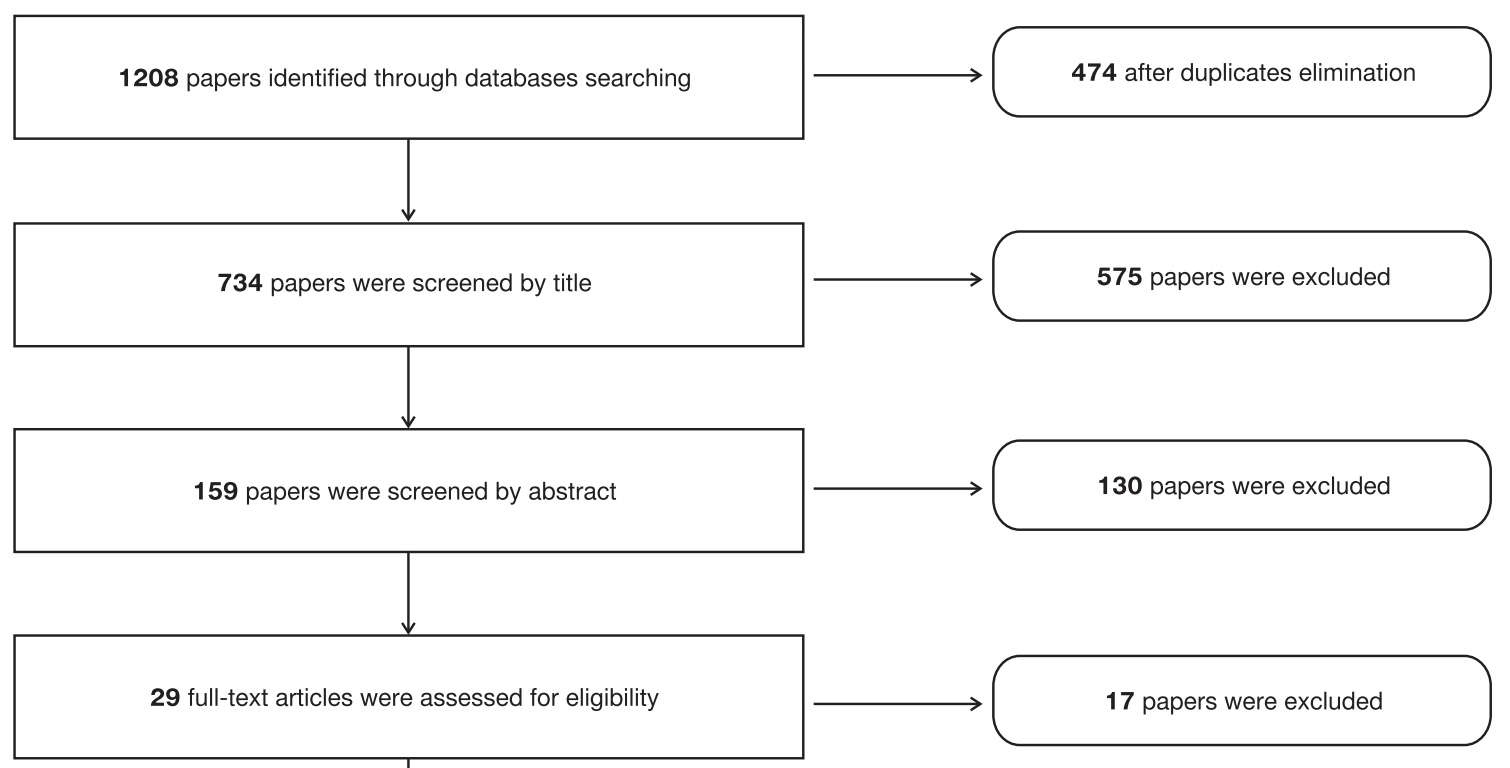

12 papers included for data extraction

Figure 1. Flow chart of the literature research 
F. Palumbo, A. Fusco, C. Cortis, L. Capranica, Student-athlete migration: a systematic literature review

competing at the national level participated in one study [39], and those competing at the international level contributed to the majority $(n=11)$ of studies [18, 30, 37, 38, 40-46]. For the academic career, student-athletes enrolled at the high school level participated in 2 studies [41, 43] and the remaining 10 studies involved student-athletes enrolled at the university level.

Regarding the countries of residence of the studentathletes, the studies included multiple countries from different continents $(n=8[18,30,37,38,41-44])$, from Africa ( $n=1$ [45]), and from Europe ( $n=1$ [46]), whereas a single country (i.e., the USA) was included in 2 papers $[39,40]$. As for the final destination of migration, the USA was represented in 8 studies [30, 37, 38 , 42-46], multiple continents were represented in 2 studies [18, 40], whereas 2 studies reported migration in a single continent (Europe [41] and French Polynesia [39]). Only 8 studies reported the reasons for migration, specifically related to the dual career [18, 40, 42, 46], education [38, 39], living abroad [43], and sport [30].

Table 2 reports all the information regarding the country of origin, destination, aim of the study, sample size, and main findings of the included papers.

Building on the conceptualized student-athlete migration [30], the thematic analysis identified 3 mainlevel constructs in 8 studies only: (1) Mercenary (education: $n=2$, combining academic study and sport: $n=4$ ); (2) Ambitious (sport: $n=1$ ); and (3) Exile or expelled (living abroad: $n=1$ ); whereas 4 studies lacked the information to allow their inclusion in any category (Table 3). Finally, the quality appraisal resulted in $100 \%$ of the included studies (Table 4 ) attaining final scores ranging from 31 to 36 points (i.e., good), substantiating their inclusion in the final analysis.

\section{Discussion}

The purpose of this review was to establish and critically appraise the existing relevant scientific contributions on the dual career of migrating student-athletes. The main findings are: (1) a limited scientific interest in dual career migration, although the mobility of students, athletes, and student-athletes nowadays characterizes the globalized world; and (2) a general lack of dual career friendly environments supporting the combination of educational (university or high school) and high-level sports opportunities, which renders American colleges offering optimal opportunities to accomplish education and sport the most represented migration site of student-athletes. The present review highlighted that the desire to attain high-quality education, the willingness to live in another country, and the aspiration to practise sports at high levels were the main reasons for the migration of dual career athletes. Indeed, cross-cultural adjustments to live and play sport in a foreign country could benefit from a good self-efficacy, time management, knowledge of cultural similarities and differences facilitating the relationships with local people, and could predispose migrating student-athletes to approach college with greater self-confidence in their ability to achieve good academic scores in their new context [42]. Although the continuous political and financial EU interest and support in dual career encourage international collaboration, as well as promote the development of initiatives aiming to increase the sharing of best practice, transfer of knowledge, and cooperation between educational institutions and sports clubs for the benefit of student-athletes, many aspects still need to be addressed [47]. Among others, the recent report on the state of play concerning the implementation of the EU guidelines on dual careers of athletes envisages supplementary supra-national actions to facilitate arrangements abroad of the high mobility of athletes, as well as adequate research focused on the international dimension of dual career programmes [47].

For the purpose of the present study, it was deemed appropriate to define international student-athlete mobility as border-crossing to study and play sport in the country of destination [48]. In particular, the search strategy highlighted a paucity of studies on migrant student-athletes, with 12 articles meeting the inclusion criteria mainly based on provisional theories and not validated tools for examining push-pull factors of dual career migration. Therefore, these caveats prevent a sound interpretation of the reported pull factors, which resulted highest for the combination of academic and sport (4 studies), with respect to education (2 studies), sport (1 study), and international experience (1 study). In accordance with the archetypes of methodological fit in field research [49], the present findings position dual career migration at a nascent phase, urging further investigations based on collecting systematic data on migrating student-athletes in their countries of origin as well as their countries of destination to frame the phenomenon of European student-athletes relocating within and beyond Europe. Moreover, this study could present valuable indications to fill in the gap of knowledge in this area.

A conceptual clarification is needed to limit possible methodological flaws and mistakes in data interpretation due to different definitions. Thus, clear definitions should help distinguishing inbound (e.g., within the native country) vs. outbound (e.g., border- 


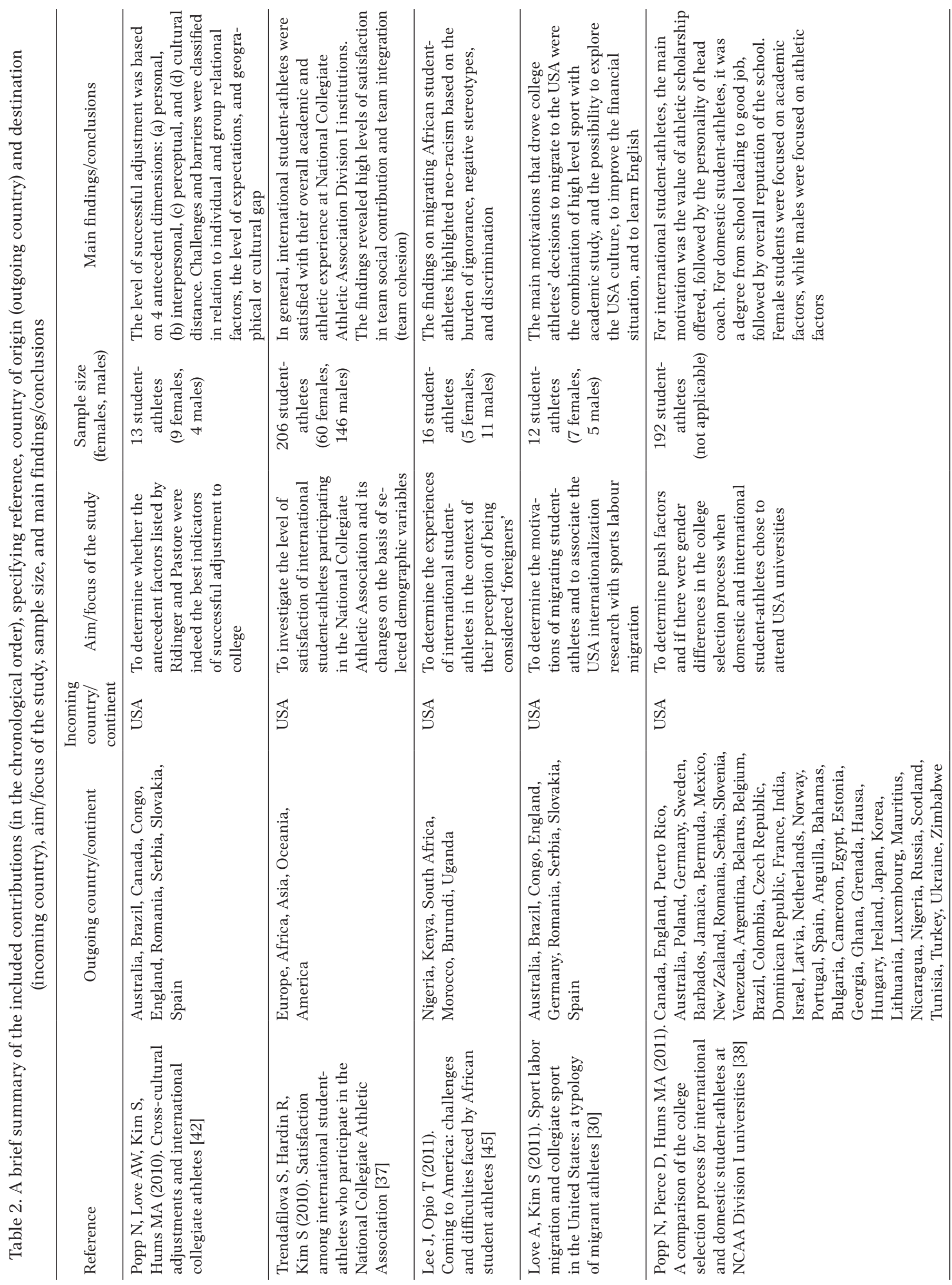




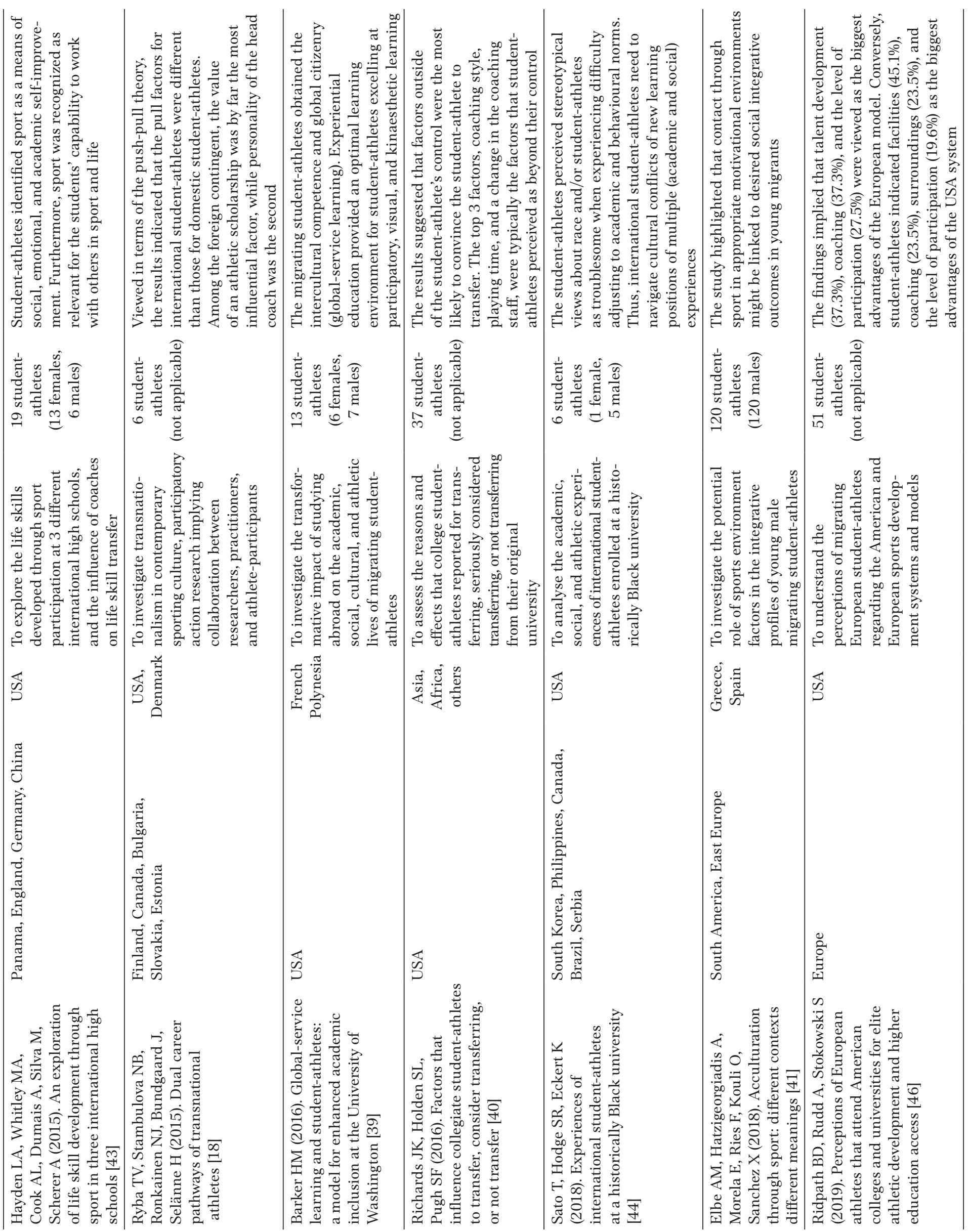


Table 3. Mapping synthesis of the 3-level construct of the selected papers $(n=12)$, including Ambitious, Exile or expelled, and Mercenary, their purpose for migration, and references

\begin{tabular}{lcc}
\hline Main level constructs & Purpose for relocation & Reference \\
\hline Ambitious & Sport & {$[30]$} \\
\hline Exile or expelled & Living abroad & {$[43]$} \\
\hline Mercenary & Education & {$[38,39]$} \\
Not applicable & Combining academic study and sport & {$[18,40,42,46]$} \\
\hline
\end{tabular}

Table 4. Quality assessment of the selected papers

\begin{tabular}{|c|c|c|c|c|c|c|c|c|c|c|}
\hline Reference & 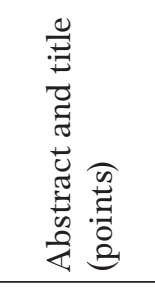 & 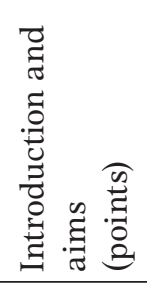 & 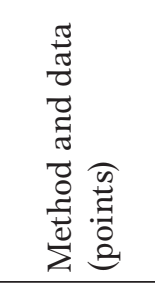 & 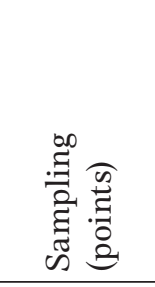 & 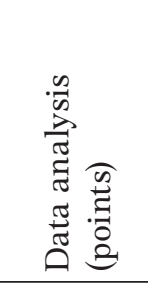 & 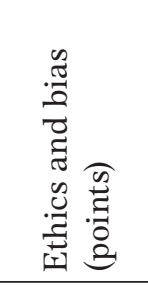 & 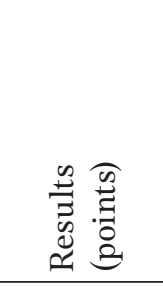 & 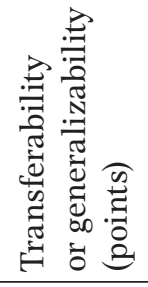 & 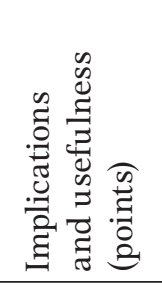 & 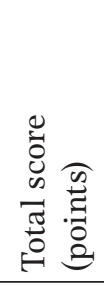 \\
\hline [42] & Good (4) & Good (4) & Good (4) & & Good (4) & Good (4) & & Fair (3) & Good (4) & (34) \\
\hline [37] & & Fair & Goo & Go & & & & Good (4) & 4) & (34) \\
\hline [45] & Good (4) & Good (4) & Good (4) & & (4) & (4) & & Good (4) & Good (4) & (35) \\
\hline [30] & Good (4) & Good (4) & Good (4) & Fair (3) & 4) & Goo & & Good (4) & Good (4) & (35) \\
\hline [38] & Good (4) & Good (4) & Good (4) & Good (4) & $\operatorname{ood}(4)$ & Goo & Go & Good (4) & (4) & (36) \\
\hline [43] & Good (4) & Good (4) & Good (4) & Fair (3) & Good (4) & Good (4) & Good (4) & Good (4) & Good (4) & (35) \\
\hline [18] & Good (4) & Good (4) & Good (4) & Fair (3) & Good (4) & Good (4) & Good (4) & Good (4) & Good (4) & (35) \\
\hline [39] & Good (4) & Good (4) & Good (4) & Fair (3) & Good (4) & Good (4) & Good (4) & Fair (3) & Fair (3) & (33) \\
\hline [40] & Good & Good (4) & Good & Good (4) & & & & Fair (3) & Good (4) & (35) \\
\hline [44] & Good & Good & Good & & & & Goo & Fair (3) & & (34) \\
\hline$[4$ & & & & & & & & (4) & & (35) \\
\hline [46] & Good (4) & Good (4) & Good (4) & Good (4) & Good (4) & Good (4) & Good (4) & Good (4) & Good (4) & (36) \\
\hline
\end{tabular}

crossing) mobility, short-term (e.g., from a few months to a year) vs. whole study programme mobility (e.g., 4 years), vertical (e.g., superior in quality) vs. horizontal (e.g., equal in quality) mobility; and mobility for the purpose of the combination of study and sport vs. for study-related and sport-related purposes.

In Europe, the short-term border-crossing mobility within the ERASMUS programme is considered a principal tool for building the personal progression of European youth [19], leading to remarkable development of international skills as well as of international career opportunities [48]. To stimulate such a European educational mobility, international partnerships between institutions, departments, and programmes have been developed to support the growing migration of students and scholars [19]. However, the ERASMUS mobility programme supports European students abroad only for one semester or one academic year, and this temporary migration might conflict with the sports commitment or competition schedules of the athletes. In fact, being mainly organized at the club level and being separate and distinct from the European educational model, the European sports system often lacks formal relationships with the educational systems [47] and schedules its competitions regardless of the academic agenda. Although the literature reports that student-athletes are more likely to achieve greater educational and labour market success as compared with their non-athlete counterparts [50], European talented athletes are challenged to maintain their sports commitments or to prioritize education to prepare for future job opportunities [16], and few of them could benefit from educational study abroad in absence of exchange agreements between Member States for transnational athletes. Furthermore, the lack of clear criteria for the status of European student-athletes and national approaches to dual career allow Member States to offer dual career services only to their national student-athletes [17]. In the context of the pervasive globalization of sport and education, further research is 
F. Palumbo, A. Fusco, C. Cortis, L. Capranica, Student-athlete migration: a systematic literature review

needed to empirically examine the migration phenomenon of student-athletes and to investigate how their flow around Europe can contribute to the development of a European dual career sports culture. Furthermore, the ERASMUS observatory could start collecting information regarding the sport participation (e.g., type of sport, competitive level, sports commitment) of the beneficiaries of its grants, which could allow largescale dual career investigations.

In presenting a unique support for athletes willing to participate at an elite sports level while receiving a university degree, the USA National Collegiate Athletic Association (NCAA) model is considered with great interest by European athletes who might not have similar opportunities in their home countries [46]. In fact, the American sport, mainly organized at the educational level, offers athletic scholarships, provides living and sports facilities, highly qualified coaching and academic teaching, and ensures academic flexibility, distance learning, support resources, and counselling, independently of the athlete's nationality [30, 51]. Therefore, international student-athletes enrol at USA universities for a whole study programme of 4 years not only to complete a bachelor degree, substantiating their acquired competencies, but also to have a 4 -year sports experience. Coherently, $67 \%$ of the eligible articles presented USA as the incoming country of student-athletes, thus implying that student-athletes are attracted by long-term border-crossing mobility in presence of well structured dual career opportunities [46]. Actually, the well structured dual career opportunities at American universities could be perceived as vertical mobility when student-athletes migrate expecting to improve their sports or education opportunities, as well as to refine their English language skills for the future transition in the labour market at the end of their sports career [30]. However, this study highlighted the American hegemony in attracting migrating student-athletes through a well-structured dual career system, which could stimulate European efforts in developing transnational dual career cooperation between Member States. In general, migrating studentathletes expect this vertical mobility upon the promises of the athletic programme of the universities, which ensure them counselling, social inclusion, and advice upon arrival. In some cases, this vertical migration is not confirmed when student-athletes report an excessive competitiveness of the NCAA colleges and the presence of authoritarian coaches holding no coaching certificates, being focused exclusively on the competition outcomes, ready to cut off players from the team if they do not perform, and not caring of their athletes' pro- gress in college [46]. Thus, moving from their incoming country with high expectations, student-athletes experience a decrease in their motivations [42].

In the context of several excellences at the educational and sports levels and a strong vocation towards cooperation between inter-university study programmes, degrees, transfer of knowledge [52], and research [53] within and beyond Europe, student-athletes could be interested in intra-European mobility for developing their education and sports career if provided adequate dual career support. As the globalized sport could greatly contribute to the process of cultural and psychological change that follows intercultural contact [41], migrating student-athletes should enter the agenda of European educational institutes and sports bodies. Thus, to implement European dual career for migrating student-athletes, the ERASMUS programme should consider the opportunity to extend the duration of its support beyond a 1-year period for this special population. Furthermore, university courses offered in English could constitute an additional aspect favouring student-athlete intra-European migration. Finally, the European Commission [47] provided guidelines on the minimum skills and competences required for coaches, who are urged to be aware of the principles and importance of the athlete's dual career and to be prepared to act as a supporting mentor.

Another relevant issue to be considered is the lack of a validated instrument to investigate the push-pull factors for student-athletes' migration. Although a plethora of studies have applied a specific tool to investigate the motivation of American [54], Brazilian [55, 56], European [57-59], Korean [60], and United Arab Emirates [61] student-athletes towards their dual career, sport, and academic careers, there is a need of conceptual and quantitative knowledge on the reasons for dual career migration, which could clarify pushpull factors and challenges, thus contributing to this line of research. In particular, future studies are necessary to understand whether migrating studentathletes encounter difficulties in their transition to the labour market or whether they can profit from their international experience as migrating studentathletes to increase their job opportunities as compared with their non-migrating counterparts.

The main limitation of this systematic literature review was the deliberate inclusion of papers related to migrating student-athletes published in English in peer-reviewed journals. This approach intended to provide a sound evidence-based development of guidelines built on a solid theoretical background of the migrating student-athletes' perceived needs and challenges. 
Nevertheless, to contribute to this academic field, future research may investigate non-English-language literature and the complexity and variety of sporting and educational contexts of former migrating studentathletes and the subsequent impact of their migration experience as perceived at the end of their sporting career.

Despite its limitation, the present review could provide important information to stimulate future research on the dynamic and evolving phenomenon of studentathletes' migration as well as future European actions supporting the mobility of talented and elite athletes pursuing dual career in European countries.

\section{Funding}

This research has been supported by the European Commission (599400 Ref. Number 2017-2112/001-001; Call EAC/A03/2016, Project number: 590400-EPP1-2017-1-AT-SPO-SCP).

\section{Disclosure statement}

No author has any financial interest or received any financial benefit from this research.

\section{Conflict of interest}

The authors state no conflict of interest.

\section{References}

1. Condello G, Capranica L, Doupona M, Varga K, Burk V. Dual-career through the elite university student-athletes' lenses: the international FISU-EAS survey. PLoS One. 2019;14(10):e0223278; doi: 10.1371/journal. pone. 0223278.

2. Stambulova NB, Ryba TV, Henriksen K. Career development and transitions of athletes: the International Society of Sport Psychology Position Stand Revisited. Int J Sport Exerc Psychol. Published online: March 10, 2020; doi: 10.1080/1612197X.2020.1737836.

3. Wylleman P, Lavallée D. A developmental perspective on transitions faced by athletes. In: Weiss M (ed.), Developmental sport and exercise psychology: a lifespan perspective. Morgantown: Fitness Information Technology; 2004; 503-524.

4. Capranica L, Millard-Stafford ML. Youth sport specialization: how to manage competition and training? Int J Sports Physiol Perform. 2011;6(4):572-579; doi: 10.1123/ijspp.6.4.572.

5. Stambulova NB, Wylleman P. Dual career development and transitions. Psychol Sport Exerc. 2015;21:1-134; doi: 10.1016/j.psychsport.2015.05.003.

6. European Commission. White Paper on Sport. Brussels: Commission of the European Communities; 2007. Available from: https://eur-lex.europa.eu/legal-content/EN/ TXT/PDF/?uri=CELEX:52007DC0391\&from=EN.
7. International Olympic Committee. Olympic Agenda 2020. Lausanne: International Olympic Committee; 2014.

8. European Parliament. Combining sports and education: support for athletes in the EU Member States. Luxembourg: European Parliament; 2003. Available from: https://www.europarl.europa.eu/thinktank/en/document.html?reference=DG-4-CULT_ET(2004)341532.

9. Halleux V. EU sport policy: an overview. European Parliament; 2015; doi: 10.2861/29626.

10. European Parliament. European Parliament resolution of 2 February 2017 on an integrated approach to sport policy: good governance, accessibility and integrity. Brussels: European Parliament; 2017. Available from: http:// www.europarl.europa.eu/sides/getDoc.do?type= TA\&reference $=$ P8-TA-2017-0012\&language $=$ EN\&rin $\mathrm{g}=\mathrm{A} 8-2016-0381$.

11. Arai A, Ko YJ, Ross S. Branding athletes: exploration and conceptualization of athlete brand image. Sport Manage Rev. 2014;17(2):97-106; doi: 10.1016/j.smr.2013.04.003.

12. Kleissner A, Grohall G, European Parliament, European Parliament Committee on Culture and Education, European Parliament Directorate-General for Internal Policies of the Union, Policy Department B: Structural and Cohesion Policies. Research for Cult Committee: the economic dimension of sport. Brussels: European Parliament; 2015.

13. De Bosscher V, Shibli S, Westerbeek H, van Bottenburg M. Successful elite sport policies: an international comparison of the sports policy factors leading to international sporting success (Spliss 2.0) in 15 nations. Aachen: Meyer \& Meyer Sport; 2015.

14. European Commission. EU guidelines on dual careers of athletes: recommended policy actions in support of dual careers in high-performance sport. Brussels: European Commission; 2012. Available from: https:// ec.europa.eu/assets/eac/sport/library/documents/dual-career-guidelines-final_en.pdf.

15. Aquilina D, Henry I. Elite athletes and university education in Europe: a review of policy and practice in higher education in the European Union Member States. Int J Sport Policy. 2010;2(1):25-47; doi: 10.1080/19406941 003634024.

16. European Commission. Study on the minimum quality requirements for dual career services. Luxembourg: European Commission; 2016; doi: 10.2766/345818.

17. Capranica L, Guidotti F. Research for cult committee qualifications/dual careers in sports. Brussels: European Parliament: Directorate-General for Internal Policies. Policy Department B: Structural and Cohesion Policies: Culture and Education; 2016. Available from: http:// www.europarl.europa.eu/RegData/etudes/STUD/ 2016/573416/IPOL_STU(2016)573416_EN.pdf.

18. Ryba TV, Stambulova NB, Ronkainen NJ, Bundgaard J, Selänne H. Dual career pathways of transnational athletes. Psychol Sport Exerc. 2015;21:125-134; doi: 10.1016/j.psychsport.2014.06.002. 
F. Palumbo, A. Fusco, C. Cortis, L. Capranica, Student-athlete migration: a systematic literature review

19. European Commission. Erasmus+ project results: enriching lives, opening minds. European Commission; 2017. Available from: https://ec.europa.eu/programmes/ erasmus-plus/resources/documents/erasmus-leafletenriching-lives-opening-minds_en.

20. González CR, Mesanza RB, Mariel P. The determinants of international student mobility flows: an empirical study on the Erasmus programme. High Educ. 2011;62:413-430; doi: 10.1007/s10734-010-9396-5.

21. Thibault L. Globalization of sport: an inconvenient truth. J Sport Manag. 2009;23(1)1-20; doi: 10.1123/jsm.23.1.1.

22. Walters G, Rossi G. Labour market migration in European football: key issues and challenges. Birkbeck Sport Business Centre Research Paper Series. 2009;2(2):1-163.

23. Engh MH, Agergaard S, Maguire J. Established-outsider relations in youth football tournaments: an exploration of transnational power figurations between Scandinavian organizers and African teams. Soccer Soc. 2013;14(6):781-798; doi: 10.1080/14660970.2013. 843907.

24. Poli R. Understanding globalization through football: the new international division of labour, migratory channels and transnational trade circuits. Int Rev Sociol Sport. 2010;45(4):491-506; doi: 10.1177/10126902103 70640.

25. Magee J, Sugden J. “The world at their feet”: professional football and international labor migration. J Sport Soc Issues. 2002;26(4):421-437; doi: 10.1177/019373250 2238257.

26. Maguire J. Global sport: identities, societies, civilizations. Cambridge: Polity; 1999.

27. Fulbright. Fulbright Scholar Program. Available from: https://www.cies.org/about-us.

28. McCray S, Kuchem D. Bridging the gap: perspectives on nationally competitive scholarships. Fayetteville: University of Arkansas Press; 2019.

29. European Commission. The plus of ERASMUS+. Available from: https://ec.europa.eu/programmes/erasmusplus/node_en.

30. Love A, Kim S. Sport labor migration and collegiate sport in the United States: a typology of migrant athletes. J Issues Intercoll Athl. 2011;4:90-104.

31. King R, Findlay A, Ahrens J. International student mobility literature review. Bristol: Higher Education Funding Council for England; 2010.

32. Guidotti F, Cortis C, Capranica L. Dual career of European student-athletes: a systematic literature review. Kinesiol Slov. 2015;21(3):5-20.

33. Khan KS, Kunz R, Kleijnen J, Antes G. Five steps to conducting a systematic review. J R Soc Med. 2003;96(3): 118-121; doi: 10.1258/jrsm.96.3.118.

34. Moher D, Liberati A, Tetzlaff J, Altman DG, PRISMA Group. Preferred reporting items for systematic reviews and meta-analyses: the PRISMA statement. PLoS Med. 2009;6(7):e1000097; doi: 10.1371/journal.pmed.1000097.

35. Hawker S, Payne S, Kerr C, Hardey M, Powell J. Appraising the evidence: reviewing disparate data sys- tematically. Qual Health Res. 2002;12(9):1284-1299; doi: 10.1177/1049732302238251.

36. Lorenc T, Petticrew M, Whitehead M, Neary D, Clayton S, Wright K, et al. Crime, fear of crime and mental health: synthesis of theory and systematic reviews of interventions and qualitative evidence. Public Health Res. 2014;2(2):1-398; doi: 10.3310/phr02020.

37. Trendafilova S, Hardin R, Kim S. Satisfaction among international student-athletes who participate in the National Collegiate Athletic Association. J Intercoll Sport. 2010;3(2):348-365; doi: 10.1123/jis.3.2.348.

38. Popp N, Pierce D, Hums MA. A comparison of the college selection process for international and domestic student-athletes at NCAA Division I universities. Sport Manage Rev. 2011;14(2):176-187; doi: 10.1016/j.smr. 2010.08.003.

39. Barker HM. Global-service learning and student-athletes: a model for enhanced academic inclusion at the University of Washington. Ann Glob Health. 2016;82(6): 1070-1077; doi: 10.1016/j.aogh.2016.11.001.

40. Richards JK, Holden SL, Pugh SF. Factors that influence collegiate student-athletes to transfer, consider transferring, or not transfer. Sport J. 2016;19:1-3.

41. Elbe AM, Hatzigeorgiadis A, Morela E, Ries F, Kouli O, Sanchez X. Acculturation through sport: different contexts different meanings. Int J Sport Exerc Psychol. 2018; 16(2):178-190; doi:10.1080/1612197X.2016.1187654.

42. Popp N, Love AW, Kim S, Hums MA. Cross-cultural adjustments and international collegiate athletes. J Intercoll Sport. 2010;3(1):163-181; doi: 10.1123/jis.3.1.163.

43. Hayden LA, Whitley MA, Cook AL, Dumais A, Silva M, Scherer A. An exploration of life skill development through sport in three international high schools. Qual Res Sport Exerc Health. 2015;7(5):759-775; doi: 10.1080/2159676X.2015.1011217.

44. Sato T, Hodge SR, Eckert K. Experiences of international student-athletes at a historically Black university. J Int Students. 2018;8(2):696-723; doi: 10.5281/zenodo. 1250372 .

45. Lee J, Opio T. Coming to America: challenges and difficulties faced by African student athletes. Sport Educ Soc. 2011;16(5):629-644; doi:10.1080/13573322.2011. 601144.

46. Ridpath BD, Rudd A, Stokowski S. Perceptions of European athletes that attend American colleges and universities for elite athletic development and higher education access. J Glob Sport Manag. 2019;5(1):34-61; doi: 10.1080/24704067.2019.1636402.

47. European Commission. Guidelines regarding the minimum requirements in skills and competences for coaches. Luxembourg: European Commission; 2020. Available from: https://op.europa.eu/en/publication-detail/ -/publication/8f28e3a0-6f11-11ea-b735-01aa75ed71a1/language-en/format-PDF/source-122543310.

48. Teichler U. Internationalisation trends in higher education and the changing role of international student 
mobility. J Int Mobil. 2017;1(5):177-216; doi: 10.3917/ jim.005.0179.

49. Edmondson AC, McManus SE. Methodological fit in management field research. Acad Manage Rev. 2007; 32(4):1246-1264; doi:10.5465/AMR.2007.26586086.

50. Carlson D, Scott L, Planty M, Thompson J. What is the status of high school athletes 8 years after their senior year? Washington: National Center for Education Statistics; 2005.

51. McCormack C, Walseth K. Combining elite women's soccer and education: Norway and the NCAA. Soccer Soc. 2013;14(6):887-897; doi: 10.1080/14660970.2013. 843927.

52. European Commission. Erasmus+: Find an opportunity. Available from: https://ec.europa.eu/programmes/ erasmus-plus/opportunities/help/find-opportunity_en.

53. European Research Council. Available from: https:// erc.europa.eu.

54. Gaston-Gayles JL. The factor structure and reliability of the Student Athletes' Motivation toward Sports and Academics Questionnaire (SAMSAQ). J Coll Stud Dev. 2005;46(3):317-327; doi: 10.1353/csd.2005.0025.

55. Quinaud RT, Gonçalves CE, Capranica L, Carvalho HM. Factors influencing student-athletes' identity: a multilevel regression and poststratification approach. Percept Mot Skills. 2020;127(2):432-447; doi: 10.1177/00315 12519899751.

56. Quinaud RT, Fernandes A, Gonçalves CE, Carvalho HM. Student-athletes' motivation and identity: variation among Brazilian and Portuguese university studentathletes. Psychol Rep. 2020;123(5):1703-1723; doi: $10.1177 / 0033294119892885$.

57. Guidotti F, Minganti C, Cortis C, Piacentini MF, Tessitore A, Capranica L. Validation of the Italian version of the Student Athletes' Motivation toward Sport and Academics Questionnaire. Sport Sci Health. 2013;9: 51-58; doi: 10.1007/s11332-013-0145-x.

58. Lupo C, Tessitore A, Capranica L, Rauter S, Topic MD. Motivation for a dual-career: Italian and Slovenian student-athletes. Kinesiol Slov. 2012;18(3):47-56.

59. Lupo C, Guidotti F, Gonçalves CE, Moreira L, Topic MD, Bellardini $\mathrm{H}$, et al. Motivation towards dual career of European student-athletes. Eur J Sport Sci. 2015;15(2): 151-160; doi: 10.1080/17461391.2014.940557.

60. Park S, Hong S, Lee M. Validation of the Student Athletes' Motivation towards Sports and Academics Questionnaire to Korean student-athletes. J Exerc Rehabil. 2015;11(4):220-227; doi: 10.12965/jer.150202.

61. Fortes PC, Rodrigues G, Tchantchane A. Investigation of academic and athletic motivation on academic performance among university students. Int J Trade Econ Finance. 2010;1(4):367-372; doi: 10.7763/IJTEF.2010. V1.65. 